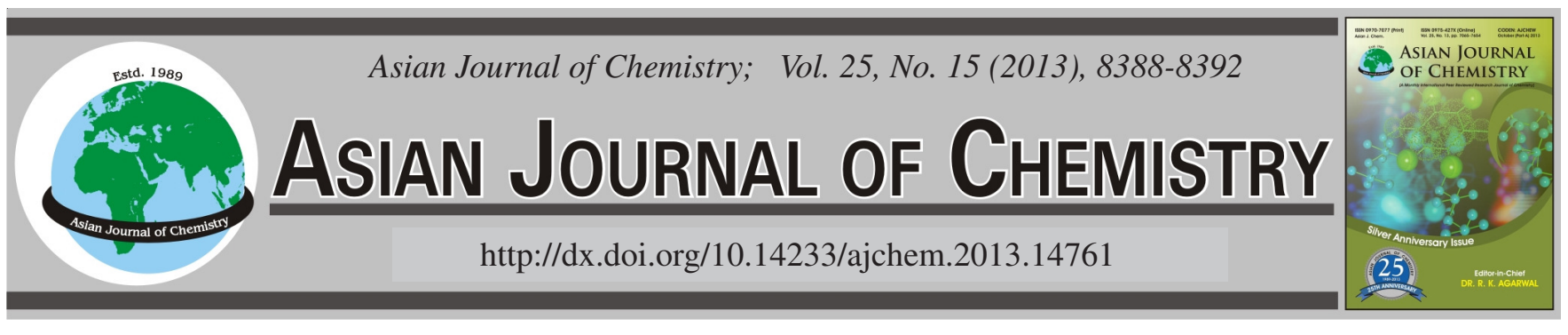

\title{
Sensitive Electrochemical Determination of Luteolin in Chrysanthemum morifolium Ramat Using a Copper Nanocluster/Graphene-Modified Electrode
}

TIEJIN YANG* and Du JiANG

College of Chemistry and Chemical Engineering, Qiqihar University, Qiqihar-161006, P.R. China

*Corresponding author: E-mail: dujiang131@yahoo.com.cn

A simple and highly sensitive electrochemical method was developed for the determination of trace-level luteolin, based on the copper
nanocluster/graphene-modified electrode. Scanning electron microscopy were used for the characterization of the distribution of the
copper nanoclusters on the graphene matrix. The composite of the copper nanocluster/graphene was investigated by the electrochemical
characterization of cyclic voltammetry and electrochemical impedance spectroscopy. The preliminary study shows that the sensor has
synergistic electrocatalytic activity to the oxidation of luteolin. The linear range for the detection of the luteolin is $7.0 \times 10^{-7}-3 \times 10^{-6} \mathrm{M}$,
a low detection limit of $3 \times 10^{-8} \mathrm{M}$. Experiment results also showed that the sensor has good reproducibility and is interference free. The
analytical performance of this sensor has been evaluated for detection of luteolin in Chrysanthemum morifolium Ramat as a real sample.

Key Words: Luteolin, Copper nanoclusters, Chrysanthemum morifolium Ramat, Graphene, Electrochemical analysis.

ᄂ - - - - - - - - - - - - - - - - - - - - - - - - - - -

\section{INTRODUCTION}

The flower of Chrysanthemum morifolium Ramat (CM) has been used as Chinese traditional healthy food and medicine for hundreds of years. It is used for drink (just like tea) more usual than for medicine, especially in the summer. The flower of Chrysanthemum morifolium contains flavonoids, amino acids, vitamins and some trace elements. In addition to wellknown antioxidant values ${ }^{1,2}$, it has various biological features such as cardiovascular protection effects ${ }^{3}$, protection against terminal tumors ${ }^{4}$ and antiinflammatory features ${ }^{5}$.

Flavonoids are a group of polyphenolic compounds widely distributed in plant. They are naturally occurring antioxidants to be utilized in a great number of health products ${ }^{6}$. Luteolin, a crucial member of the flavones, widely occurs in vegetables, fruits and natural herbal drugs, such as Flos chrysanthemi, Caulis lonicerae japonicae and Flos lonicerae. Aside from its effects of vasodilation ${ }^{7}$ and cancer prevention ${ }^{8}$, recent studies have also shown that it could enter the cellular nuclei and suppress the oxidative damage of DNA ${ }^{9}$. So far, a great deal of methods have been reported for the determination of luteolin in flavonoids, including high-performance liquid chromatography (HPLC) ${ }^{10}$, capillary electrophoresis ${ }^{11}$, spectrophotometry ${ }^{12}$, gas chromatography $(\mathrm{GC})^{13}$, etc. Most of these methods have their own shortcomings, such as timeconsuming, low sensitivity and complicate experimental process.
Recently, graphene has been considered as a "rising star" carbon material, attracting enormous interests. Graphene is made of monolayers of two-dimensional honeycomb graphite type carbon ${ }^{14,15}$. This unique nanostructure material has high surface area, excellent electrical conductivity and electron mobility at room temperature, robust mechanical properties and flexibility ${ }^{16}$. The special properties of graphene may provide insight to fabricate novel biosensors for virtual applications. The high surface area is helpful in increasing the surface loading of the target enzyme molecules on the surface. The excellent conductivity and small band gap are favourable for conducting electrons from the biomolecules. Recently, researches have demonstrated that graphene also possesses excellent electrochemical catalytic activity and should be a novel electrode modified material with excellent performance. For instance, Wang's group found that graphene can improve sensitivity for lead and cadmium ion detections ${ }^{17,18}$.

The nanomaterials such as graphene (GR) and transition metallic nanoparticles (NPs) have been widely applied in sensors and biosensors. Transition metallic nanoparticles, including gold, platimum, palladium, copper, nickel and silver, can be used to increase electrochemical activities with high sensitivity and fast amperometric method. In the current study, an effective sensor of luteolin was introduced with catalytic oxidation by electrodepositing the $\mathrm{Cu}$ nanoclusters onto the electrode modified with nafion-solubilized graphene. The sensor was then used for the analysis of the luteolin in real 
Chrysanthemum morifolium Ramat and it provided high sensitivity and stability, fast current response and good reproducibility and selectivity.

\section{EXPERIMENTAL}

Luteolin (purity $>99 \%$ ) were obtained from J \& K-ACIoS (serial number: 62696). Nf (5\%) was obtained from Aldrich (USA). $\mathrm{CuSO}_{4}$ was purchased from Beijing Chemical Reagent (Beijing, China). All other reagents were of analytical grade and doubly distilled water was used throughout.

The electrochemical experiments were performed with a CHI660C electrochemical workstation (Shanghai, China). All experiments were carried out by a three-electrode system with a glassy carbon electrode (GCE, $\Phi=3 \mathrm{~mm}$ ) as the working electrode, a Pt wire as the auxiliary electrode and an $\mathrm{Ag} / \mathrm{AgCl} /$ $3 \mathrm{M} \mathrm{KCl}$ as the reference electrode.

Transmission electron microscopic (TEM) images were obtained by using a JEOL JEM-100SX microscope (Japan). The modified electrodes were characterized by SEM (S-4300, Hitachi High-Tech, Japan). The SEM equipped with EDS (EX250, HORIBA, Japan) were employed for the composition analysis.

Sample preparation: Chrysanthemum morifolium were purchased from a QQHE pharmacy (Qiqihar, China). The luteolin sample was extracted from the Chrysanthemum morifolium as described. At first, the Chrysanthemum morifolium $(2 \mathrm{~g})$ was extracted with $50 \mathrm{~mL}$ of ethyl acetate at $80^{\circ} \mathrm{C}$ for $1.5 \mathrm{~h}$. Then, the sample was cooled and filtered. The mixed suspension was centrifuged at $3000 \mathrm{rpm}$ for $5 \mathrm{~min}$. The supernatant was filtered through $0.45 \mu \mathrm{m}$ membrane and diluted to $100 \mathrm{~mL}$ with water in a calibrated flask.

Synthesis of graphene: Graphite was put into a mixture of $12 \mathrm{~mL}$ concentrated $\mathrm{H}_{2} \mathrm{SO}_{4}, 2.5 \mathrm{~g} \mathrm{~K}_{2} \mathrm{~S}_{2} \mathrm{O}_{8}$ and $2.5 \mathrm{~g} \mathrm{P}_{2} \mathrm{O}_{5}$. The solution was heated to $80{ }^{\circ} \mathrm{C}$ and kept stirring for $5 \mathrm{~h}$ using oil-bath. The mixture was diluted with deionized water $(500 \mathrm{~mL})$. The product was obtained by filtering using $0.2 \mu \mathrm{m}$ nylon film and dried naturally. The product was re-oxidized by Hummers and Offeman method ${ }^{19}$ to produce the graphite oxide. Exfoliation was carried out by sonicating $0.1 \mathrm{mg} / \mathrm{mL}$ graphite oxide dispersion for $1 \mathrm{~h}$. Reduction of graphite oxide was carried out by adding $0.5 \mathrm{~mL}$ hydrazine into the solution of $50 \mathrm{mg}$ graphite oxide powder in $20 \mathrm{~mL}$ water after sonicating for $1 \mathrm{~h}$ and kept stirring for $24 \mathrm{~h}$ at $50{ }^{\circ} \mathrm{C}$. Finally, black hydrophobic powder of graphene was obtained by filtration and dried in vacuum ${ }^{20}$.

The morphology of the graphene was observed by TEM. Fig. 1 shows the TEM image of graphene nanosheets, illustrating the flake-like shapes of graphene.

Preparation of the modified electrodes: GC electrode was polished before each experiment with $1,0.3$ and $0.05 \mu \mathrm{m}$ $\alpha$-alumina powder (CHI Instrument, Shanghai, China) in sequence, rinsed thoroughly with doubly distilled water between each polishing step, ultrasonicated in 1:1 $\mathrm{HNO}_{3}$, ethanol and doubly distilled water and allowed to dry at room temperature. Then $1 \mathrm{mg}$ graphene was dispersed in $1.0 \mathrm{~mL}$ of $0.5 \%$ nafion. The electrochemical synthesis of $\mathrm{Cu}$ nanoclusters on the graphene surface is shown in Scheme-I. GC electrode were modified by a $4 \mu \mathrm{L}$ drop of graphene-nafion or nafion

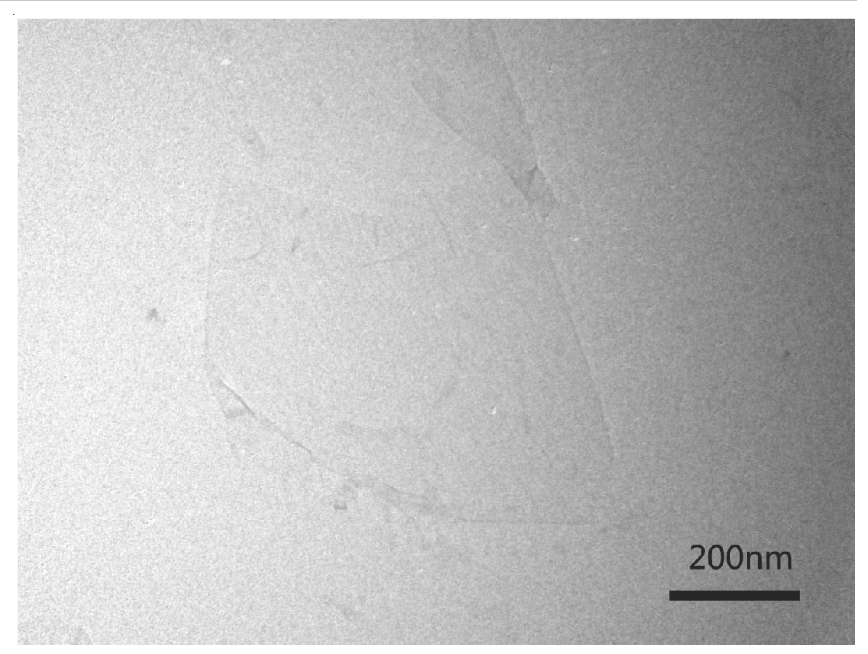

Fig. 1. TEM image of graphene in water

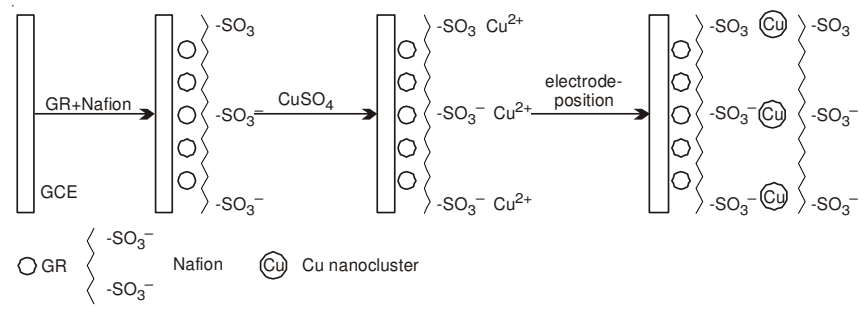

Scheme-I: Preparation process of the modified electrode

solution and dried in air. Thereafter $\mathrm{Cu}$ nanoclusters were deposited onto the above modified electrode from the solutions of $2.0 \mathrm{mM} \mathrm{CuSO}_{4}$ in $0.1 \mathrm{M} \mathrm{Na}_{2} \mathrm{SO}_{4}$ under fixed applied potential of $-0.2 \mathrm{~V}$ for $200 \mathrm{~s}$, obtaining high sensitivity and reproducibility of the electrodes. The electrodes were rinsed with water, modified by a $4 \mu \mathrm{L}$ drop of $0.5 \%$ nafion on the surface and dried and stored at $4{ }^{\circ} \mathrm{C}$ in a refrigerator.

\section{RESULTS AND DISCUSSION}

All the experiments were conducted at room temperature in a conventional electrochemical cell. The active surface area was estimated by steady-state voltammetry in a solution of 15 $\mathrm{mM} \mathrm{K}_{4}\left[\mathrm{Fe}(\mathrm{CN})_{6}\right]$ with $0.2 \mathrm{M} \mathrm{KCl}$ as the supporting electrolyte. The electrochemical impedance spectroscopy (EIS) measurements were also performed in $10 \mathrm{mM}\left[\mathrm{Fe}(\mathrm{CN})_{6}\right]^{3-14-}$ solution containing $0.1 \mathrm{M} \mathrm{KCl}$ and plotted in the form of complex plane diagrams (Nyquist plots). They were recorded with a frequency range of $0.01 \mathrm{~Hz}$ to $10 \mathrm{kHz}$. The amplitude of the applied sine wave potential is $5 \mathrm{mV}$, with a formal potential $0.211 \mathrm{~V}$. Cyclic voltammetry experiments were carried out in quiescent solution with a scan rate of $100 \mathrm{mV} \mathrm{s}^{-1}$ in an electrochemical cell filled with $5.0 \mathrm{ml}$ of $50 \mathrm{mM}$ PBS $=4$. The current-time curves were recorded at $0.65 \mathrm{~V}$ under stirring. All experimental solutions were deoxygenated by high-purity nitrogen for $10 \mathrm{~min}$.

Electrodeposition of $\mathrm{Cu}$ nanoclusters on graphene: Copper-nanoparticles were deposited onto graphene-GC electrode from the solutions of $2 \mathrm{mM} \mathrm{CuSO}_{4}$ in $0.1 \mathrm{M} \mathrm{Na}_{2} \mathrm{SO}_{4}$ under fixed applied potential of $-0.2 \mathrm{~V}$ for $200 \mathrm{~s}$.

The prepared electrodes were characterized by TEM. Fig. 2 shows that $\mathrm{Cu}$ nanoclusters were deposited on the graphene matrix and that the size is $30-100 \mathrm{~nm}$, indicating that the 


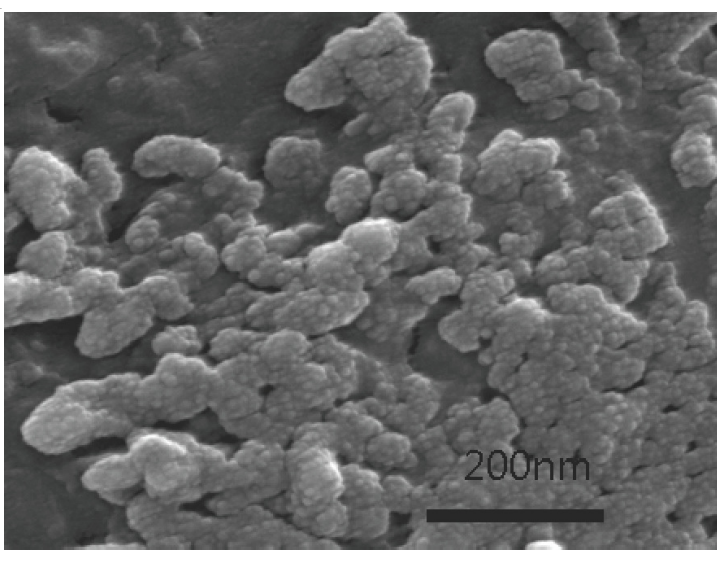

Fig. 2. SEM image of $\mathrm{Cu}$ nanoclusters on $\mathrm{GR}$

larger size of copper nanoclusters may be an aggregation of a much finer size of copper nanoparticles. The results are ascribed to the following two possible reasons: on the one hand, as the size increases, some neighboring particles have a tendency to coalesce. On the other hand, considering the random distribution of particles, there certainly are some particles that suffer from marked diffusion interference and then form large-size $\mathrm{Cu}$ nanoclusters ${ }^{21}$.

Fig. 3 illustrated the EDS of the copper nanoparticles/ graphene modified electrode. The EDS conforms the additional signals corresponding to $\mathrm{Cu}$ elements besides the element .However from the percentages of $\mathrm{Cu}$ which are $90.01 \%$, it indicated that some $\mathrm{Cu}$ particles were oxidized. But the results further conform that the copper nanoparticles and graphene were modified on the glassy electrode.

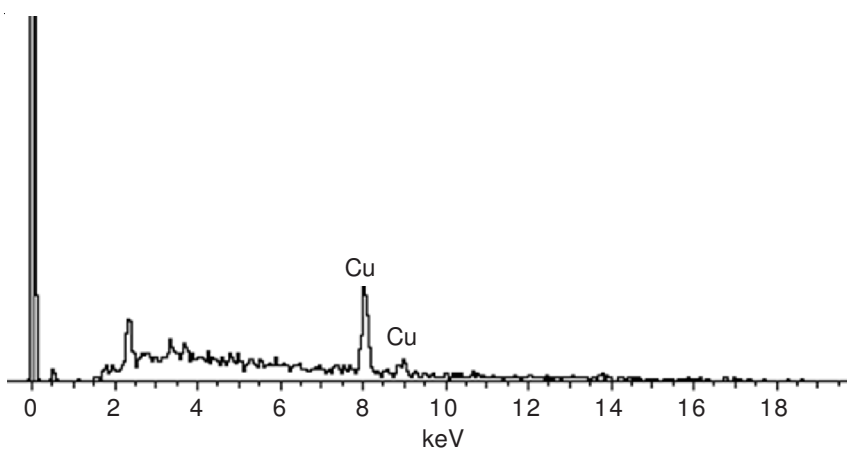

Fig. 3. EDS of $\mathrm{Cu}-\mathrm{NPs} / \mathrm{GR} / \mathrm{GCE}$

Electrochemical characterization: Fig. 4 compares the $\mathrm{CV}$ of a bare GCE with that of the four modified GCEr in $15 \mathrm{mM}$ $\mathrm{K}_{4}\left[\mathrm{Fe}(\mathrm{CN})_{6}\right]$ with $0.2 \mathrm{M} \mathrm{KCl}$ at $20 \mathrm{mV} \mathrm{s}^{-1}$ Quasi-reversible one-electron redox behaviour of ferricyanide ion was observed on the bare GCE (Fig. 4 line a) with a peak separation $(\Delta E p)$ of $90 \mathrm{mV}$ at $20 \mathrm{mV} \mathrm{s}^{-1}$. After the electrode was modified with nafion, the lowest peak current (Ip) and the largest $\Delta \mathrm{Ep}$ were observed (Fig. 4 line b). Nafion is negatively charged and hinders the diffusion of ferricyanide ion toward the electrode surface. For the deposition of $\mathrm{Cu}$ nanoclusters on the nafionmodified electrode (Fig. 4 line c), the lowest current peak was increased and $\Delta \mathrm{Ep}$ was decreased compared with that of the nafion-modified electrode, indicating that $\mathrm{Cu}$ nanoclusters played a role in the increase of the electroactive surface area. Fig. 4 (line d) presents the voltammetric effect of ferricyanide

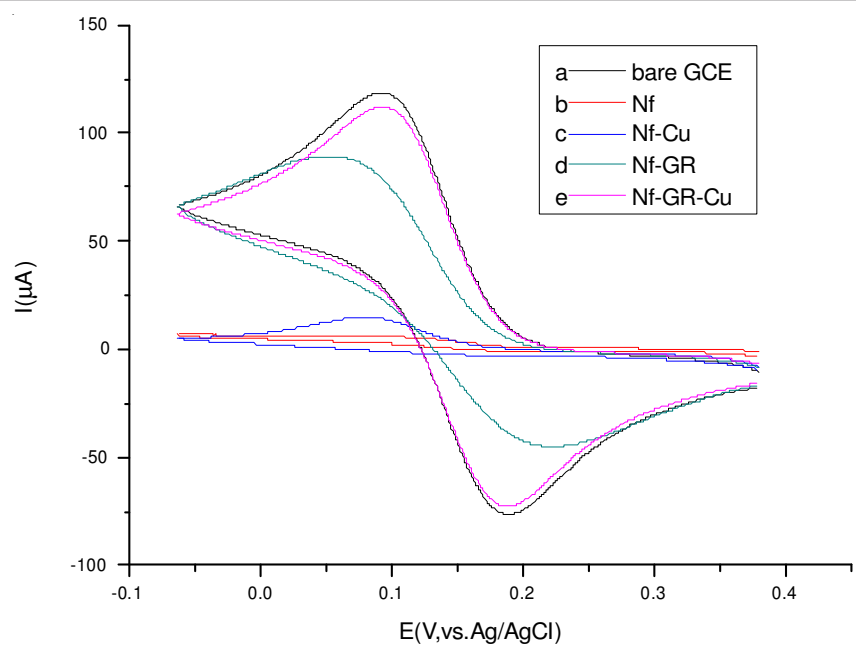

Fig. 4. $\mathrm{CV}$ of the electrodes in $15 \mathrm{mM} \mathrm{Fe}(\mathrm{CN})_{6}{ }^{4-}$ with $0.2 \mathrm{M} \mathrm{KCl}$ at $20 \mathrm{mV}$ $\mathrm{s}^{-1}$ for bare GCE and four modified electrodes

ion on the graphene-nafion-modified electrode because graphene have a catalytically active surface and a very high aspect ratio. However, the lowest current peak of the modified graphene-nafion electrode was decreased compared with that of the bare GCE, due mainly to the blocking behaviour of nafion. With the application of copper-graphene-nafion composite film. The obtained voltammetric response was comparable to that of the bare electrode (Fig. 4 line e). The voltammograms show that copper-graphene-nafion film was effectively immobilized on the GCE surface and provided the necessary conduction pathways, resulting in promoting the electron transfer between the interface of analyte and electrode just like a nanoscale electrode. They also indicate that the electrode had a large electroactive surface area.

EIS was applied to monitor the whole process of the preparation of modified electrodes. This can give useful information of the impedance changes on the electrode surface between each step.

Fig. 5 shows the results of EIS for the bare GCE and four modified electrodes in the presence of equimolar $\left[\mathrm{Fe}(\mathrm{CN})_{6}\right]^{3-14}$. The EIS includes a semicircular part and a linear part. The semicircular part at higher frequencies corresponds to the electron transfer limited process and the diameter is equivalent to the electron transfer resistance (Rct). The linear part at lower frequencies corresponds to the diffusion process. Using an appropriate equivalent circuit to fitting the data. During the fabrication, significant differences were observed. The electron transfer resistnace of the bare GCE is $226 \Omega$ (Fig. 5 line a).After GCE was modified with $\mathrm{Nf}$, electron transfer resistnace increased markedly to $12,000 \Omega$, perhaps due to the $\mathrm{Nf}$ film acting as a barrier and blocking interfacial charge transfer (Fig. 5, line b).The results for the electrodes modified with graphene and $\mathrm{Cu}$ nanoclusters are shown in Fig. 5(lines c and d); electron transfer resistnace was decreased to 730 and 3400 $\Omega$, respectively. When the copper-graphene-nafion composite was applied to modify the GCE, electron transfer resistnace was decreased to $400 \Omega$. The results show that the graphene or $\mathrm{Cu}$ nanocluster film was successfully immobilized on the GCE surface and the results are consistent with the CV results (Fig. 4). 


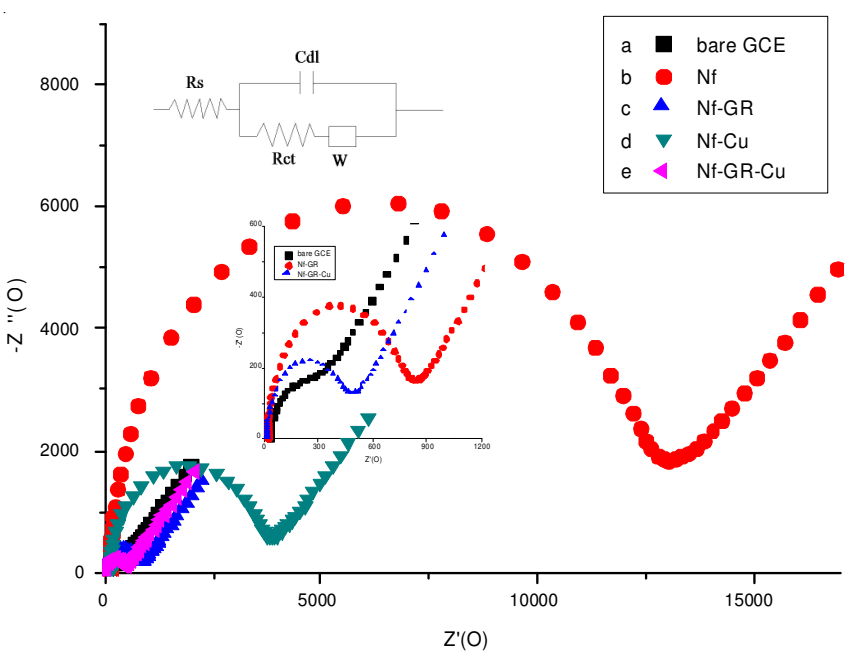

Fig. 5. Nyquist plots of EIS in $10 \mathrm{mM} \mathrm{Fe}(\mathrm{CN})_{6}^{3-1 / 4-}$ at $0.211 \mathrm{~V}$ for bare GCE and four modified electrodes. Inset: Magnified for bare GCE, NfGR-GCE and Nf-Cu-GR-GCE

Electrocatalysis of luteolin: Cyclic voltammetric studies were conducted in deoxygenated PBS $=4$ with modified electrodes (Fig. 6). The current was reduced substantially after fabricating with nafion (Fig. 6, line a). When graphene-nafion film was formed on the GCE, the current was increased (Fig. 6 , line b). The results revealed the electronic transfer between the graphene and the GCE surface. For the electrode modified with $\mathrm{Cu}$ nanoclusters, it displayed oxidation/reduction features of $\mathrm{Cu}$ and was similar to the $\mathrm{CV}$ of a bare $\mathrm{Cu}$ electrode (Fig. 6 line c). When fabricating $\mathrm{Cu}-\mathrm{GR}-\mathrm{GCE}$, a large current was observed (Fig. 6, line d). Anodic peaks at -1 and $1 \mathrm{~V}$ are attributed to the conversion of $\mathrm{Cu}(0)$ to $\mathrm{Cu}(\mathrm{II})$. The cathodic peaks at 1 and $-1 \mathrm{~V}$ are ascribed to the transition of $\mathrm{Cu}(\mathrm{II})$ to $\mathrm{Cu}(0)$.

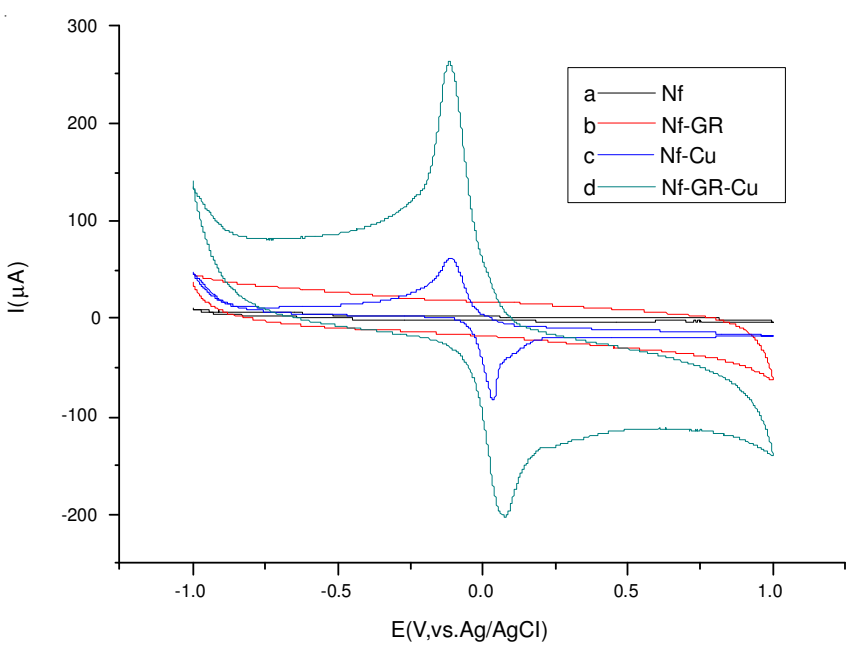

Fig. 6. $\mathrm{CV}$ of various modified electrodes in $50 \mathrm{mM}$ PBS $=4$ at $100 \mathrm{mV} \mathrm{s}^{-1}$

Fig. 7 shows $\mathrm{CV}$ of the $\mathrm{Cu}-\mathrm{GR}-\mathrm{GCE}$ without and with $1.0 \mathrm{mM}$ luteolin in $50 \mathrm{mM}$ PBS $=4$ at a scan rate of $100 \mathrm{mV}$ $\mathrm{s}^{-1}$. Although the exact mechanism for the oxidation of luteolin in $\mathrm{PBS}=4$ at $\mathrm{Cu}$ electrodes or $\mathrm{Cu}$-modified electrodes is still not known with certainty, $\mathrm{Cu}$ (III) species have been proposed to act as an electron transfer mediator ${ }^{22-24}$. Fig. 7 inset illustrates the response current of luteolin by various modified electrodes at an applied potential of $0.8 \mathrm{~V}$. No response current of nafionmodified GCE was observed and the response currents of

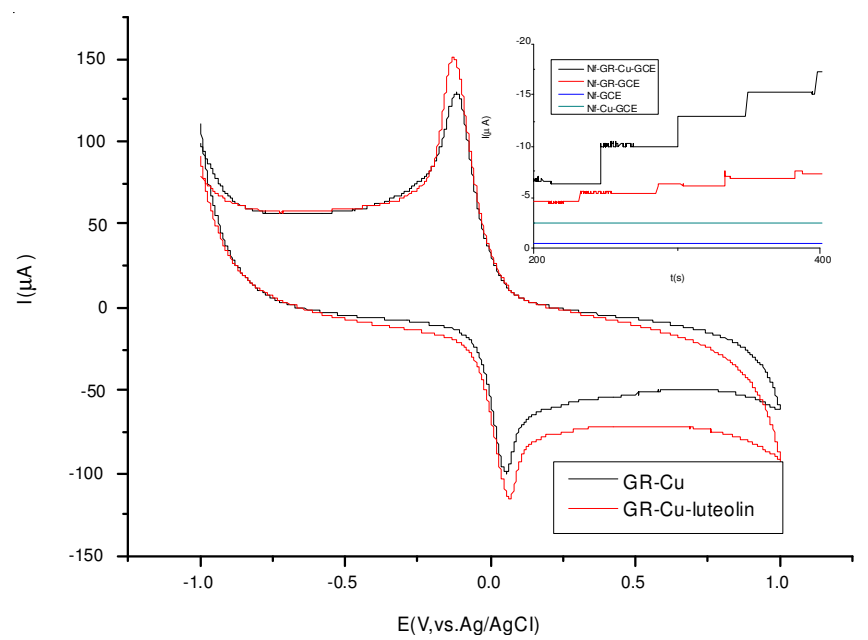

Fig. 7. $\mathrm{CV}$ of the $\mathrm{Cu}-\mathrm{GR}-\mathrm{GCE}$ without and with $1.0 \mathrm{mM}$ luteolin in 50 $\mathrm{mM}$ PBS $=4$ at $100 \mathrm{mV} \mathrm{s}^{-1}$ Inset: Steady-state current-time response of various modified electrodes to $1 \mathrm{mM}$ luteolin in $50 \mathrm{mM}$ PBS $=4$ at $0.8 \mathrm{~V}$

$\mathrm{Cu}-\mathrm{GCE}$ and GR-GCE were small. Cu-GR-GCE had large and fast response currents.

Fig. 8 illustrates current-time plots for the sensor experimental conditions with successive step changes of luteolin concentration. The calibration curve for the sensor is shown in the left inset of the figure. The sensor displays a linear range $\left(7.0 \times 10^{-8}-3.0 \times 10^{-6} \mathrm{M}\right.$ luteolin) with a correlation coeffcient of 0.9984 , a detection limit of $3 \times 10^{-8} \mathrm{M}$ at a signal/noise ratio of 3 . It can be attributed to the increase of electroactive surface area and the synergistic electrocatalytic activity by combining $\mathrm{Cu}$ nanoclusters with graphene. The relative standard deviation of eleven successive scans was $8.78 \%$, which indicated that the modified electrode had an excellent reproductively.

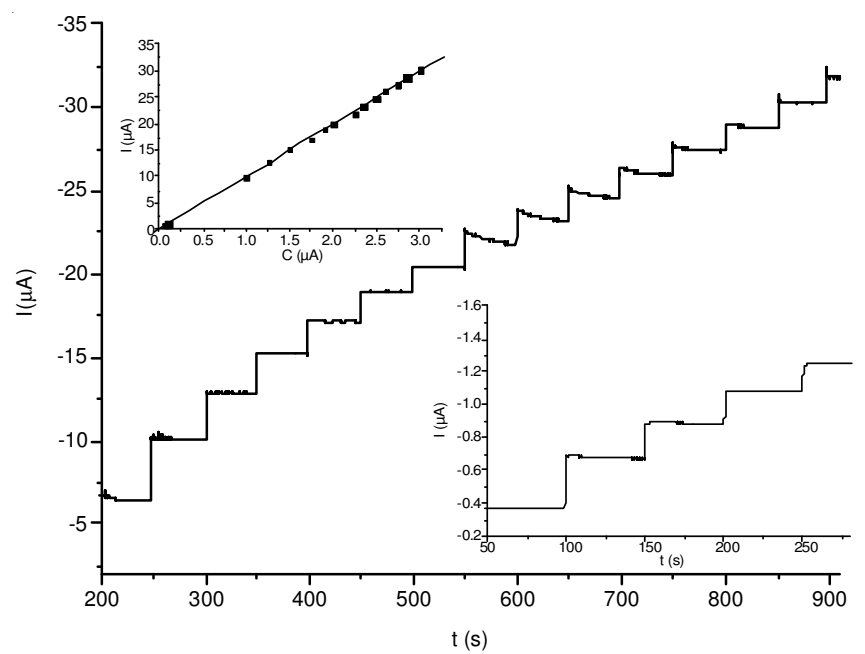

Fig. 8. Steady-state current-time responses of Nf-Cu-GR-GCE to various concentrations of luteolin in $50 \mathrm{mM}$ PBS $=4$ at $0.8 \mathrm{~V}$. Left inset: Calibration curve. Right inset: Current-time response to $0.1 \mathrm{mM}$ luteolin

Interferences: To evaluate the interferences of some foreign species on the determination of the current response of luteolin. Other possible interferents, such as $100 \mu \mathrm{M}$ lysine, $100 \mu \mathrm{M}$ citric acid, $100 \mu \mathrm{M}$ glucose, $100 \mu \mathrm{M}$ cyclodextrin, $100 \mu \mathrm{M}$ lactose, $100 \mu \mathrm{M}$ saturated starch, were individually 
and simultaneously added into a standard solution containing $0.6 \mu \mathrm{M}$ luteolin. The results indicated that on interference effect (signal change $<5 \%$ ) on the determination of luteolin was observed.

Determination of luteolin in Chrysanthemum morifolium: To demonstrate the performance of the proposed method in real sample analysis, the content of luteolin in Chrysanthemum morifolium was analyzed using current-time method based on the Nf-Cu-GR-GCE. It was found that the content of luteolin in Chrysanthemum morifolium was $3.12 \pm 0.04 \mathrm{mg} \mathrm{g}^{-1}(\mathrm{n}=8)$, close to $3.52 \pm 0.06 \mathrm{mg} \mathrm{g}^{-1}(\mathrm{n}=3)$ determined by high-performance liquid chromatography (HPLC). This means that the proposed voltammetry using Nf-Cu-GR-GCE is applicable for the fast determination of luteolin in Chrysanthemum morifolium. In addition, the recovery test was carried out by adding a known amount of luteolin standard into the sample and then analyzed according to the same procedure. The value of recovery is in the range from $95.5-101.4 \%$, also indicating that this method is reliable and feasible.

\section{Conclusion}

Copper nanoclusters have been electrochemically deposited on the layer of graphene matrix prepared on GCE, constructing a luteolin biosensor. The newly developed luteolin biosensor presents a number of attractive features such as high sensitivity and stability, good reproducibility and selectivity. It is ascribed to the increase of electroactive surface area, the synergistic electrocatalytic activity combining $\mathrm{Cu}$ nanoclusters with graphene and the three-dimensional porous structure of the $\mathrm{Cu}$ nanoclusters. The content of luteolin in Chrysanthemum morifolium was successfully determined with this Nf-Cu-GRGCE, indicating that the Nf-Cu-GR-GCE would be promising for the fast voltammetric determination of the luteolin in Chrysanthemum morifolium and in other real samples.

\section{REFERENCES}

1. H.J. Kim and Y.S. Lee, Planta Med., 71, 871 (2005).

2. T. Wang, H.D. Jiang, Y.P. Ji and J.H. Xu, J. Chin. Med. Mater., 24, 122 (2001) in Chinese.

3. H. Jiang, Q. Xia, W. Xu and M. Zheng, Pharmazie, 59, 565 (2004).

4. M. Miyazawa and M. Hisama, Biosci. Biotechnol. Biochem., 67, 2091 (2003).

5. M. Ukiya, T. Akihisa, K. Yasukawa, Y. Kasahara, Y. Kimura, K. Koike, T. Nikaido and M. Takido, J. Agric. Food Chem., 49, 3187 (2001).

6. G.J. Volikakis and C.E. Efstathiou, Talanta, 51, 775 (2000).

7. H.D. Jiang, Q. Xia, X.X. Wang and J.F. Song, Pharmazie, 60, 444 (2005).

8. R.P. Samy, P. Gopalakrishnakone and S. Ignacimuthu, Chem. Biol. Interact., 164, 1 (2006)

9. K. Kazuki, U. Mari, Y. Hiroaki and H. Takashi, Arch. Biochem. Biophys., 455, 197 (2006).

10. S.M. Wittemer and M. Veit, J. Chromatogr. B, 793, 367 (2003).

11. X.Q. Xu, L.S. Yu and G.N. Chen, J. Pharm. Biomed. Anal., 41, 493 (2006).

12. I. Baranowska and D. Rarog, Talanta, 55, 209 (2001).

13. C.S. Liu, Y.S. Song, K.J. Zhang, J.C. Ryu, M. Kim and T.H. Zhou, J. Pharm. Biomed. Anal., 13, 1409 (1995).

14. A.K. Geim and K.S. Novoselov, J. Nat. Mater, 3, 183 (2007).

15. K.S. Novoselov, A.K. Geim, S.V. Morozov, D. Jiang, Y. Zhang, S.V. Dubonos, I.V. Grigorieva and A.A. Firsov, Science, 306, 666 (2004).

16. S. Stankovich, D.A. Dikin, G.H.B. Dommett, K.M. Kohlhaas, E.J. Zimney, E.A. Stach, R.D. Piner, S.T. Nguyen and R.S. Ruoff, Nature, 442, 282 (2006).

17. J. Li, S. Guo, Y. Zhai and E. Wang, Anal. Chim. Acta, 649, 196 (2009).

18. J. Li, S. Guo, Y. Zhai and E. Wang, Electrochem. Commun., 11, 1085 (2009).

19. W. Hummers and R. Offeman, J. Am. Chem. Soc., 80, 1339 (1958).

20. Y. Wang, Y.M. Li, L.H. Tang, J. Lu and J.H. Li, Electrochem. Commun., 11, 889 (2009).

21. L. Cao, P. Diao, T. Zhu and Z. Liu, J. Phys. Chem. B, 108, 3535 (2004).

22. V.G. Gavalas, S.A. Law, J.C. Ball, R. Andrews and L.G. Bachas, Anal. Biochem., 329, 247 (2004).

23. Y. Lin, X. Cui and X. Ye, Electrochem. Commun., 7, 267 (2005).

24. C.M. Welch and R.G. Compton, Anal. Bioanal. Chem., 384, 601 (2006). 